\title{
Oral food challenges in a specialised allergy outpatient clinic in Sao Paolo, Brazil
}

\author{
Rozalem Ana Carolina*, Renata Cocco Rodrigues, Lucila Oliveira Camargo Lopes, Marcia Mallozi Carvalho, \\ Dirceu Sole
}

From Food Allergy and Anaphylaxis Meeting 2014

Dublin, Ireland. 9-11 October 2014

\section{Background}

Oral food challenge (OFC) is the most reliable method to diagnose food allergy in suspected children. The aim of this study was to describe the profile of patients undergone to OFC in the Division of Allergy and Clinical Immunology, Federal University of Sao Paulo, especially for cow/s milk (CM).

\section{Methods}

A retrospective study of chart analysis of 171 patients undergone to 220 OFC, between June/2007 and Feb/ 2014. Food tests comprised CM, egg, soy,peanuts, nuts, seafood, meat, chicken, tartrazine, chocolate, wheat and coconut. Patients were evaluated according to the type of CM's challenge (open or double-blind placebo-controlled), aim of the procedure (diagnosis or follow up tolerance), symptoms, body mass index, time of breastfeeding, age at first reaction, family history of food allergy, presence of other atopic diseases (asthma, allergic rhinitis and atopic dermatitis) and skin prick test.

\section{Results}

$65 \%$ of patients were male $(n=111)$ with median age of 3 years and 2 months. The most common tested foods were CM $(n=148)$, egg $(n=22)$ and soy $(n=19)$. CM's challenges were: negative in 109 (74\%), inconclusive in 4 (3\%) and positive in 34 (23\%) tests (27 open food challenge and 7 double-blind placebo-controlled). From patients who had a positive OFC, $52 \%$ had referred cutaneous symptoms, $22 \%$ gastrointestinal symptoms, $19 \%$ respiratory symptoms and $7 \%$ claimed to have had anaphylaxis. When they undergone to OFC, cutaneous symptoms were observed in $68 \%$ and $5 \%$ had an anaphylaxis episode. 35\% of children elicited symptoms after less than $1 \mathrm{ml}$ ingestion

Federal University of Sao Paolo, Sao Paolo, Brazil of CM. $67 \%$ of all reactions were classified as mild (skin and/or upper respiratory tract) and $18 \%$ as severe reaction (skin and lower respiratory tract). Among the group that passed OFC, $17 \%(n=18 / 109)$ were in a CM free diet just because of wheezing or recurrent respiratory tract infection.

\section{Conclusion}

Although there are some difficulties in performing OFC in the routine, there are multiple discrepancies between referred symptoms and diagnosis of food allergies. CM responds for the great majority of food allergy in this population.

Published: 30 March 2015

doi:10.1186/2045-7022-5-S3-P78

Cite this article as: Ana Carolina et al: Oral food challenges in a specialised allergy outpatient clinic in Sao Paolo, Brazil. Clinical and Translational Allergy 2015 5(Suppl 3):P78.

Submit your next manuscript to BioMed Central and take full advantage of:

- Convenient online submission

- Thorough peer review

- No space constraints or color figure charges

- Immediate publication on acceptance

- Inclusion in PubMed, CAS, Scopus and Google Scholar

- Research which is freely available for redistribution

Submit your manuscript at www.biomedcentral.com/submit
( Biomed Central 